\title{
Flexural Behaviour of Textile Reinforced Concrete Composites: Experimental and Numerical Evaluation
}

\author{
Natalie Williams Portal $^{1}$, Lars Nyholm Thrane ${ }^{2}$, Karin Lundgren ${ }^{3}$ \\ ${ }^{1}$ CBI Swedish Cement and Concrete Research Institute, Borås, Sweden and \\ Department of Civil and Environmental Engineering - Structural Engineering, \\ Chalmers University of Technology, Gothenburg, Sweden \\ Natalie.williamsportal@cbi.se,+461051668 87
}

${ }^{2}$ Department of Building Technology - Concrete, Danish Technological Institute (DTI), Taastrup, Denmark

${ }^{3}$ Department of Civil and Environmental Engineering - Structural Engineering, Chalmers University of Technology, Gothenburg, Sweden

\begin{abstract}
Textile reinforced concrete (TRC) is an innovative high performance composite material which has revealed many promising attributes in various applications but test methods and reliable numerical models need to be established to reduce uncertainty and the need for extensive experimental studies. The aim of this paper was to evaluate the flexural behaviour of carbon textile reinforced TRC slabs both experimentally and numerically along with the characterization of the material and interaction level properties. The experimental results characterizing the bond behaviour were linked to the experimental behaviour of a rectangular TRC slab in bending through numerical analyses. A 2D macro-scale FE-model of the tested TRC slab was developed based on the related experimental input. Comparison of the numerical results to the experiments revealed that the flexural failure was governed by bond, and reasonable agreement was obtained in terms of crack development, deflections, maximum load, and failure mode. Accordingly, the experiments further indicated that the flexural behaviour of TRC slabs is greatly influenced by the bond quality.
\end{abstract}

\section{Keywords}

Textile reinforced concrete (TRC); Flexural behaviour; Bond behaviour; Finite element; Textile materials 


\section{Introduction}

Textile reinforced concrete (TRC) has been coined as a versatile high performance composite material, yet it has not been sufficiently acknowledged due to a lack of design specifications. Test methods and databases in combination with reliable numerical models need to be established to reduce uncertainty. Furthermore, design standards are not formalized for TRC such that extensive experimental programs are still needed to acquire approval for each individual application (Lorenz et al. 2013).

The non-linear behaviour of TRC is typically characterized by means of flexural (Peled et al. 1999; Rempel et al. 2015; Schladitz et al. 2012; Yin et al. 2013), tensile (Colombo et al. 2013; Jesse 2004) and pull-out tests (Lorenz et al. 2013; $\mathrm{Xu}$ and Li 2007). Considering the case of a load bearing sandwich façade panel, the structure can face load combinations which could involve, i.e. shear and tensile forces, as well as bending moments (Shams et al. 2014). Accordingly, numerous experiments need to be conducted to gain sufficient understanding of the combined behaviours. In such design cases, it is most valuable to make use of a simplified model taking into consideration homogenized special characteristics of TRC, i.e. assuming bond-slip behaviour between textile and concrete (Hegger et al. 2006). Other modelling levels could additionally be applied to investigate more detailed aspects such as the behaviour of each filament (Banholzer et al. 2006) or crack bridging properties of yarns (Hegger et al. 2006) but these can become computationally expensive and required input parameters are difficult to quantify.

The one-way flexural behaviour of TRC in the form of thin slabs (Krüger 2004; Peled et al. 1999) or as a beam strengthening solution (Schladitz et al. 2012) has been typically studied by means of four-point bending tests. Early investigations of the bearing behaviour of thin TRC specimens reinforced by AR-glass and carbon textiles were presented in e.g. Hegger and Voss (2008) and the specimens reinforced by a hybrid textile mesh of carbon and E-glass yarns was shown in Yin et al. (2013). Despite the available research findings on this topic, a differing combination of textile and cementitious matrix requires experimental investigation, which is aimed for in this study on a particular carbon textile reinforced concrete combination. 
In this paper, it was of interest to observe the effect of high-performance carbon textile fabric on the flexural behaviour of rectangular slabs with a thickness of 50 $\mathrm{mm}$, which could be applied for façade panels. The thin thickness leads to a lightweight structure, and is made possible by the use of non-corrosive nature of textiles. Moreover, the complex interaction between the matrix and reinforcement pertaining to the same carbon reinforced TRC used in the slabs was quantified by means of pull-out tests. An approach linking the presented experimental methods on various levels, i.e. material, interaction and component, to a simplified numerical model is additionally addressed in this paper. The application of simplified macroscale finite element (FE) modelling is proposed to gain a better understanding of the failure mechanism and crack development of a rectangular one-way TRC slab in bending which is typically challenging to capture experimentally.

\section{Materials}

TRC specimens included in this work were composed of one layer of textile reinforcement fabric embedded in a fine-grained concrete matrix. A commercially available carbon textile fabric was applied throughout the experimental study. The matrix consisted of a self-compacting concrete having an aggregate size, $d_{\max }$, of $4 \mathrm{~mm}$. The material properties for the matrix and reinforcement are described in the following sections.

\subsection{Textile reinforcement fabric}

TRC research efforts have primarily been focused on the development of ARglass, mostly due to their overall suitable mechanical properties, cost effectiveness and availability. However, the application of carbon fibres in the form of fabrics has become the subject of recent TRC research due to the fact that this material is chemically inert (Micelli and Nanni 2004; Scheffler et al. 2009) and generally has superior properties to AR-glass in terms of tensile strength and modulus of elasticity. Carbon textile reinforcement typically consists of heavy-tow yarns, which means that they have a larger cross-sectional area. This feature can lead to a higher load-bearing capacity of a structure (Schladitz et al. 2012). General material and mechanical properties made available by the producer for the carbon textile reinforcement is given in Table 1 and an overview of the fabric is shown in 
Fig. 1. These data were further applied as input on the material level in the FE model (see Section 5). Experimental verification of these properties was not conducted in this scope of work; yet, due to the variability in test methods generally applied to characterize textile reinforcement properties, it could be worthwhile to verify these in future work.

Table 1 Properties of the investigated carbon textile reinforcement fabric.

\begin{tabular}{|l|l|l|l|l|l|l|l|l|}
\hline Material & Product & Direction & \multicolumn{2}{|l|}{ Properties } \\
\cline { 4 - 8 } & & $\begin{array}{l}\text { Yarn } \\
\text { fineness } \\
(\mathrm{tex}=\mathrm{g} / 1000 \\
\mathrm{m})\end{array}$ & $\begin{array}{l}\text { Axial } \\
\text { spacing } \\
(\mathrm{mm})\end{array}$ & $\begin{array}{l}\text { Density } \\
\left(\mathrm{kg} / \mathrm{m}^{3}\right)\end{array}$ & $\begin{array}{l}\text { Specific } \\
\text { surface } \\
\text { weight } \\
\left(\mathrm{g} / \mathrm{m}^{2}\right)\end{array}$ & $\begin{array}{l}\text { Tensile } \\
\text { strength } \\
(\mathrm{MPa})\end{array}$ & $\begin{array}{l}\text { Young's } \\
\text { modulus } \\
(\mathrm{GPa})\end{array}$ \\
\hline Carbon & $\begin{array}{l}\text { SIGRATEX } \\
\text { grid 300 } \\
(\mathrm{SGL}\end{array}$ & $\begin{array}{l}\text { Weft } \\
\left(90^{\circ}\right)\end{array}$ & $\begin{array}{l}3300 \\
(2 \text { yarns })\end{array}$ & 30 & 1800 & 300 & 1700 & 230 \\
\cline { 3 - 5 } & Warp $\left(0^{\circ}\right)$ & $\begin{array}{l}3300 \\
(2 \text { yarns })\end{array}$ & 30 & & & & \\
\hline
\end{tabular}

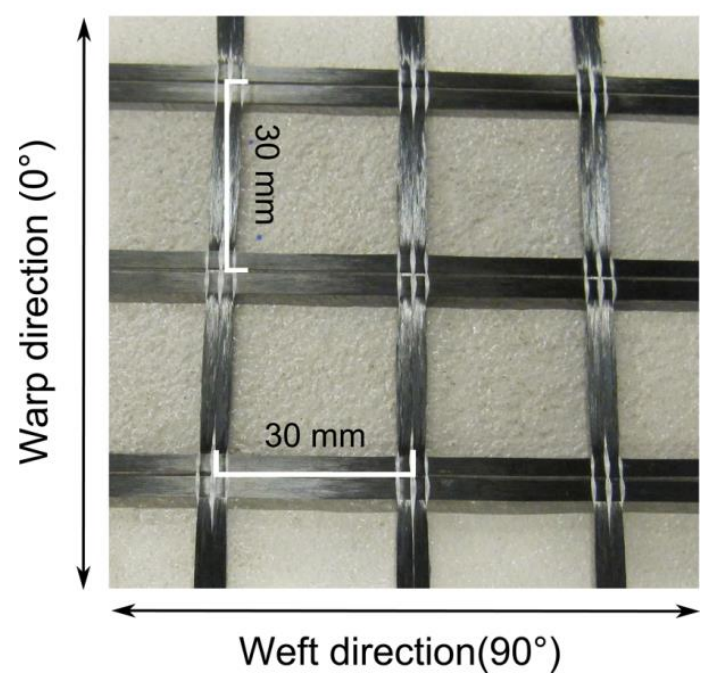

Fig. 1 Overview of the carbon textile reinforcement fabric.

\subsection{Cementitious matrix}

The cementitious matrix in TRC is generally composed of cement, fine-grained particles, cement replacement materials (CRM) and a lower water-cement ratio (w/c). When designing the mix composition, it was important to aim for a highly flowable and self-compacting material which could adequately penetrate the openings of the textile reinforcement fabric and to bear in mind the desired thickness of the structure. In TRC, a fine-grained concrete having a maximum aggregate size of less than $2 \mathrm{~mm}$ is commonly applied to achieve a superior bond 
with the textile fabric, however this could in turn increase shrinkage of the matrix and the need for larger quantities of cement paste. As such, the mix composition applied in this experimental study, listed in Table 2, had a density, $\rho$, of 2240 $\mathrm{kg} / \mathrm{m}^{3}$, w/c ratio of 0.4 and a maximum aggregate size, $d_{\max }$, of $4 \mathrm{~mm}$. The chemical admixture applied, a polymer-based superplasticizer, helped reduce the water-cement ratio which in turn allows for an increase in strength. Mineral admixtures such as fly ash and microsilica were also included primarily to improve the workability of the fresh concrete, reduce the cement quantity and possibly increase the interfacial bond with the textile fabric.

Table 2 Mix composition of the fine-grained concrete matrix (w/c 0.40).

\begin{tabular}{ll}
\hline Component & Content $\left(\mathrm{kg} / \mathrm{m}^{3}\right)$ \\
\hline Low-alkali cement CEM I 52.5 R & 406 \\
Fly ash & 121 \\
Microsilica & 22 \\
$0 / 4 \mathrm{~mm}$ sand & 1400 \\
Water & 171 \\
Superplasticizer (Glenium SKY 532-SU) & $7.6(1.4-\mathrm{wt} \%$ of binder) \\
Air entrainment (Amex SB 22) & 3 \\
\hline
\end{tabular}

General material testing of the hardened concrete was included in the scope of this experimental study, such that cylinders were cast and cured in water at $20^{\circ} \mathrm{C}$ until testing. The mean compressive strength of hardened concrete, $f_{\mathrm{c}}$, was determined experimentally on cylinders (Ø150/300 $\mathrm{mm}$ and $\varnothing 100 / 200 \mathrm{~mm})$ according to EN 12390-3 (2009). Measurements were taken at 7, 14 and 99 days, which were conducted in parallel with the flexural and pull-out test schedule. The mean compressive strength of two $\varnothing 100 / 200 \mathrm{~mm}$ cylinders at 7 and 14 days was measured as 36.1 MPa (std dev, $\sigma=0.4)$ and 47.5 $\mathrm{MPa}(\operatorname{std} \mathrm{dev}, \sigma=1.1)$, respectively. At 99 days, the mean compressive strength related to three $\varnothing 150 / 300$ mm cylinders amounted to 84.7 MPa (std dev, $\sigma=1.2$ ). The tensile strength of the hardened concrete was quantified on cylinders $(\varnothing 150 / 300 \mathrm{~mm})$ using a tensile splitting test based on EN 12390-6 (2009). This method consists of loading a concrete cylinder placed on its side in a similar testing machine to that used for compression testing. The tensile cylinder splitting strength, $f_{c t, s p}$, can be linearly related to the axial tensile strength, $f_{\mathrm{ctm}}$, using a correlation coefficient of 1.0 
according to fib Model Code 2010 (2013). The mean tensile splitting strength, $f_{c t, s p}$, was exclusively measured at 99 days for two specimens as 4.7 MPa (std dev, $\sigma=0.5$ ). The four-point bending and pull-out tests were conducted at 99 days, such that the resulting mean compressive strength of $84.7 \mathrm{MPa}$ was applied throughout the analyses enclosed in this study.

Due to the limited output of these applied experimental methods, other mechanical properties required as input in the non-linear FE analysis (Section 5) were estimated using available empirical expressions. The development of mean compressive strength with time at $20^{\circ} \mathrm{C}, f_{\mathrm{cm}}(\mathrm{t})$, was calculated according to $\mathrm{EN}$ 1992-1-1 (2008) as a relation of the cement type and 28 day mean compressive strength. Based on this expression, the cylinder compressive strength at 28 days was back calculated to be $51.6 \mathrm{MPa}$ using the measured data corresponding to 14 days. In addition, Young's modulus and the fracture energy were computed using fib Model Code 2010 to be $40 \mathrm{GPa}$ based on the compressive strength at 28 days and $99 \mathrm{~N} / \mathrm{m}$ related to the tested tensile strength, respectively. Young's modulus and the fracture energy were calculated assuming a lightweight aggregate concrete with normal weight sand. It should be noted that these applied empirical equations are not necessarily tailored to fine-grained concrete or thin specimens, such that they result in an estimation of the actual behaviour. A verification of these applied equations by means of more comprehensive experimental tests should be verified in future work.

\section{Experimental Procedures}

The scope of the experimental work encompassed the characterization of the oneway flexural behaviour of rectangular TRC slabs and the pull-out behaviour of thin TRC plates. Test specimens were cast and tested at the Danish Technological Institute (DTI). It was of interest to investigate the use of a commercially available carbon textile fabric in $50 \mathrm{~mm}$ thick slabs which could eventually be applied for façade panels. Furthermore, pull-out tests were conducted on TRC specimens composed of the same carbon textile fabric and concrete matrix investigated in the flexural tests. It should be noted that the pull-out tests have also been reported by the authors in Williams Portal et al. (2014), as such a detailed analysis of these particular tests is not provided in this paper. 


\subsection{Four-point bending}

The flexural behaviour of one-way TRC slabs was investigated by means of fourpoint bending tests. This level of investigation is considered as the component level in this study, which will be linked to the material and interaction levels via FE-modelling in Section 5. The specimens had dimensions of 1000 x $200 \times 50$ $\mathrm{mm}$ with one layer of carbon textile fabric positioned at $7.5 \mathrm{~mm}$ from the bottom edge of the slab (see Fig. 2). The warp yarns of the fabric were orientated longitudinally such that they carried the tensile load resulting from the one-way bending. One layer of carbon textile fabric corresponded to a longitudinal crosssectional area of $12.8 \mathrm{~mm}^{2}$ and a reinforcement ratio of $0.13 \%$.

(a)

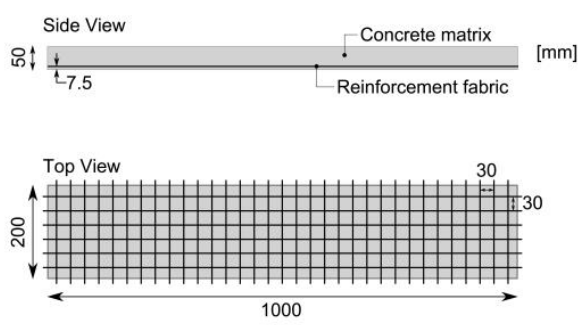

(b)

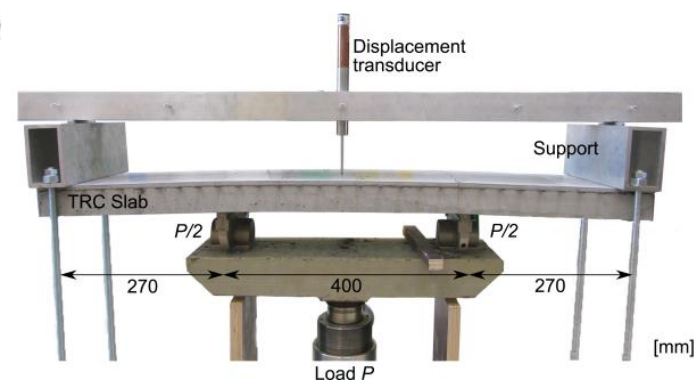

Fig. 2 Specimen geometry (a) and four-point bending test setup (b).

During casting, the edges of the fabric were fastened by the formwork such that the fabric became slightly taut yet not pre-stressed which could potentially slightly reduce the initial waviness of the fabric, increase peak load and decrease slip. The specimens were removed from their formwork after 24 hours and stored in a sealed and dry environment of $30^{\circ} \mathrm{C}$ until testing.

The four-point bending test setup, illustrated in Fig. 2 was configured in a way that the slab was placed upside down compared to when it was cast and the load was applied from beneath. The test specimen was placed on a loading beam with two steel rods separating the applied load, $P$, by a distance of $400 \mathrm{~mm}$ into two line loads, $P / 2$. The support consisted of two aluminium profiles, of which one of the steel rods and profiles could rotate at the bottom (not shown in Fig. 2) in order to ensure that both line loads were uniformly distributed across the test specimen. The load was applied by a hydraulic jack placed on a load cell. A displacement transducer was mounted on an aluminium profile on top of the test specimen to measure the midspan deflection relative to the supports. The deflection and 
corresponding applied load were measured and stored every second using a data logger.

\subsection{Pull-out tests}

A critical factor influencing the structural behaviour of TRC is in fact the complex compatibility between the textile reinforcement yarn and the matrix (Zastrau et al. 2003), primarily due to the inherent heterogeneous structure of the yarn. This interfacial behaviour, categorized as the interaction level in this study, becomes a critical input parameter for numerical models developed to analyse the component behaviour of TRC (see Section 5). Pull-out tests were applied to characterize the bond behaviour of the particularly investigated carbon reinforced TRC combination. The pull-out test setup and specimen configuration applied in this study was designed based on the double-sided unsymmetrical test by (Krüger 2004) and Lorenz and Ortlepp (2012). The pull-out tests presented, as shown in Fig. 3, were conducted on thin rectangular TRC specimens reinforced by a centrally cast layer of carbon textile fabric with the dimensions of $400 \times 100 \times 15$ $\mathrm{mm}$. The thickness of the specimens was established to simulate the cover thickness of $7.5 \mathrm{~mm}$ chosen for the rectangular TRC slabs tested in flexure. Furthermore, the specimens were divided into a shorter embedment length zone and longer anchorage length zone. The prescribed embedded length, denoted as $B$ in Fig. 3, was limited to the shorter end of the specimen by means of a single saw cut crossing the yarn to be tested and a breaking point marked by two saw cuts thus isolating an individual examined yarn. This configuration ensures that the location of crack initiation takes place at the breaking point, as such the breaking or rupture of the yarn does not necessarily take place at this location. 


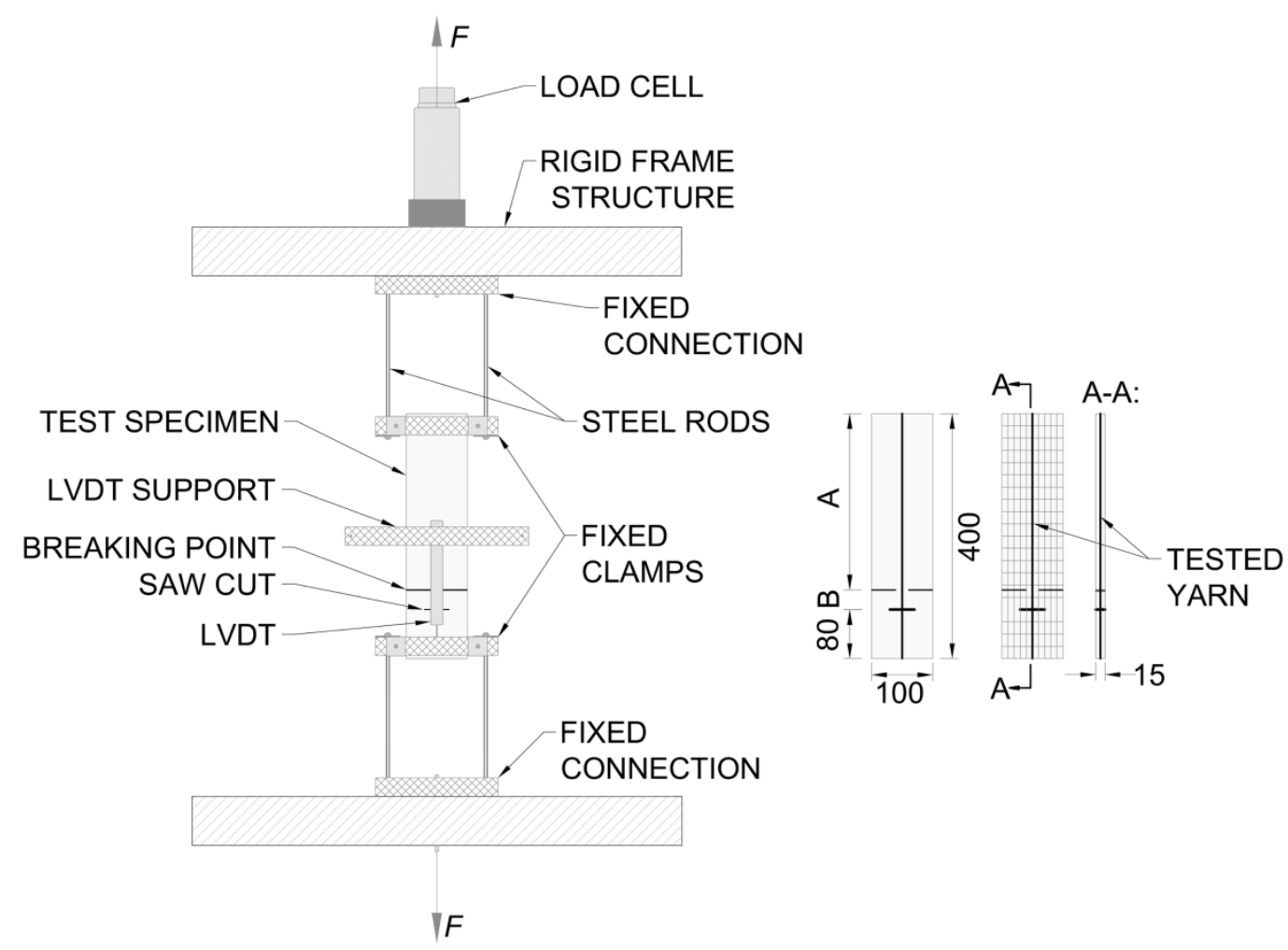

Fig. 3 Overview of the pull-out test setup (Williams Portal et al. 2014).

The embedment length was arbitrarily defined as Short $(25 \mathrm{~mm})$, Medium (50 $\mathrm{mm})$ and Long $(75 \mathrm{~mm})$. These embedment lengths were selected to be able to quantify the bond capacity and associated failure modes, e.g. pull-out and rupture. Three specimens were produced for each selected embedment length in order to obtain representative average pull-out behaviour; however, at least two specimens per embedment length group were successfully tested. Additional information regarding the experimental campaign related to the pull-out tests is reported in Williams Portal et al. (2014).

\section{Experimental Results}

The experimental results related to the one-way flexural behaviour of rectangular TRC slabs and the pull-out tests of thin TRC plates are presented in the following sections. Firstly, the flexural results pertaining to the component level are discussed in Section 4.1 according to the load versus midspan displacement relationship, crack pattern and estimated failure mode. As for the output on the interaction level, the pull-out test results and corresponding local bond-stress behaviour are presented in Section 4.2. To be able to further describe and 
understand the complex heterogeneous behaviour of TRC in bending, the observed behaviours on the interaction and component levels were further coupled in a numerical model simulating the four-point bending of the TRC slabs (see Section 5).

\subsection{Four-point bending tests}

The flexural behaviour investigated for $50 \mathrm{~mm}$ TRC rectangular one-way slabs reinforced by carbon fabric, denoted as $\mathrm{C} 1-\mathrm{C} 3$, was found to reasonably correlate within the sample set as depicted in Fig. 4. To describe the flexural behaviour of TRC, four states are typically defined to draw a parallel between conventionally reinforced concrete and TRC (Brameshuber 2006): State I (uncracked concrete), State IIA (crack formation), State IIB (crack stabilization), and State III (failure). The elastic pre-cracking state is defined as State I whereby the behaviour was primarily governed by the stiffness of the cementitious matrix. For $\mathrm{C} 1-\mathrm{C} 3$, first cracking took place at an average load of $4.3 \mathrm{kN}(\operatorname{std} \mathrm{dev}, \sigma=0.1)$ which was followed by an abrupt unloading due to the brittle nature of the load redistribution to the textile reinforcement. The extent of load drop or so-called delayed load distribution is thought to be a function of the initial geometric waviness of the fabric (Hartig et al. 2009), reinforcement area and the quality of the bond between the reinforcement and matrix. In the case of a poor bond, low filament stiffness and strength and/or minimal reinforcement amount, a greater deformation is required to activate load transfer from the matrix to the reinforcement. Moreover, State IIa was marked by the formation of multiple cracking (4-6 cracks) indicated by the apparent load jumps with minimal load increase. The crack formation eventually stabilized in State IIb, which was noted by a gain of stiffness said to be governed by the properties of the textile reinforcement (Orosz et al. 2010). This gain in stiffness is often denoted as strain hardening in the case of uniaxial tension (Brameshuber 2006) but can be seen as a form of deformation hardening in flexure. When failure was reached in State III at an average load of $8.5 \mathrm{kN}$ (std dev, $\sigma=0.1$ ) and midspan deflection of $22.6 \mathrm{~mm}$ (std dev, $\sigma=0.7)$, it is thought that a combination of pull-out and rupture occurred as can be observed in Fig. 4 where the tension side of the specimen is shown. Nevertheless, the exact mode of failure was unclear during testing, which is why this aspect was further evaluated using FE-analysis in this paper (Section 5). 


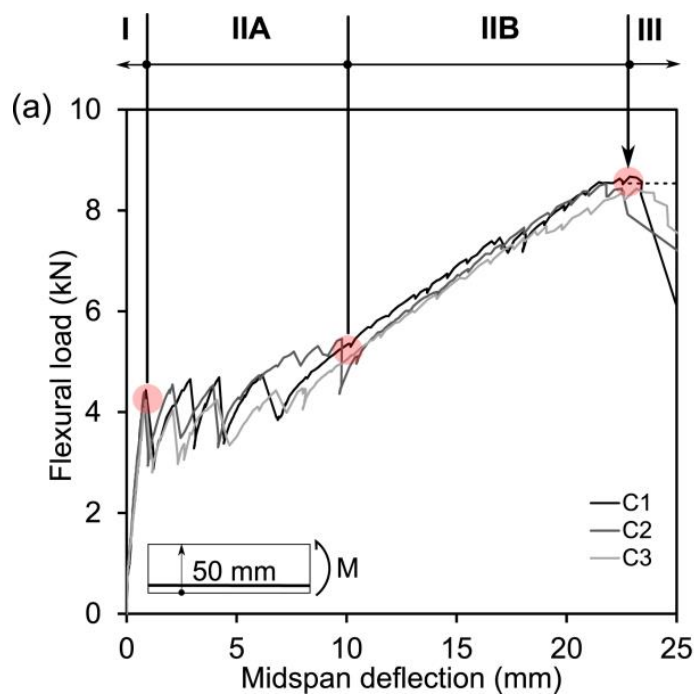

(b)

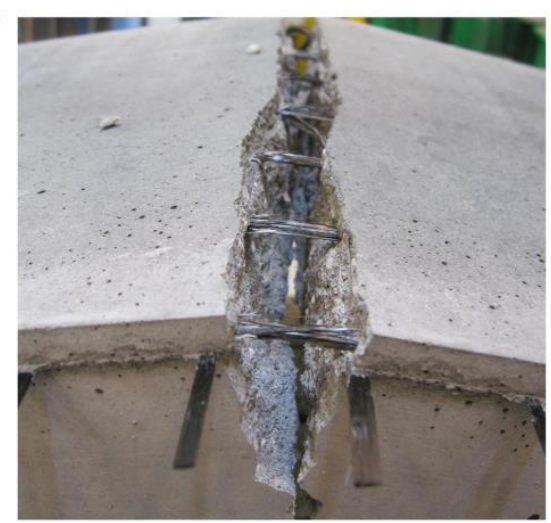

Fig. 4 Four-point bending results: flexural load versus mid-span deflection curve with indicated stages (a) and flexural crack on tension side of slab (b).

\subsection{Pull-out tests}

The average pull-out force versus total deformation relationship for all embedment lengths are presented in Fig. 5 along with the respective result scatter based on the standard error. The maximum pull-out force was observed to increase and the related deformation also marginally increased as the embedment length augmented. The maximum pull-out force corresponding to Short (25 mm) was $629 \mathrm{~N}$ (std dev, $\sigma=32), 1050 \mathrm{~N}(\operatorname{std} \mathrm{dev}, \sigma=154)$ for Medium $(50 \mathrm{~mm})$ and $1333 \mathrm{~N}$ ( $\operatorname{std} \operatorname{dev}, \sigma=298)$ for Long $(75 \mathrm{~mm})$. The scatter of the results evidently increased as the embedment length increased, which could be due to an enlarged potential for bond irregularities along the embedment length. It should be noted that during the pull-out tests, a distinct rupture failure of the carbon yarn did not occur due to insufficient embedment length and the inherent smooth surface of the carbon yarn. 

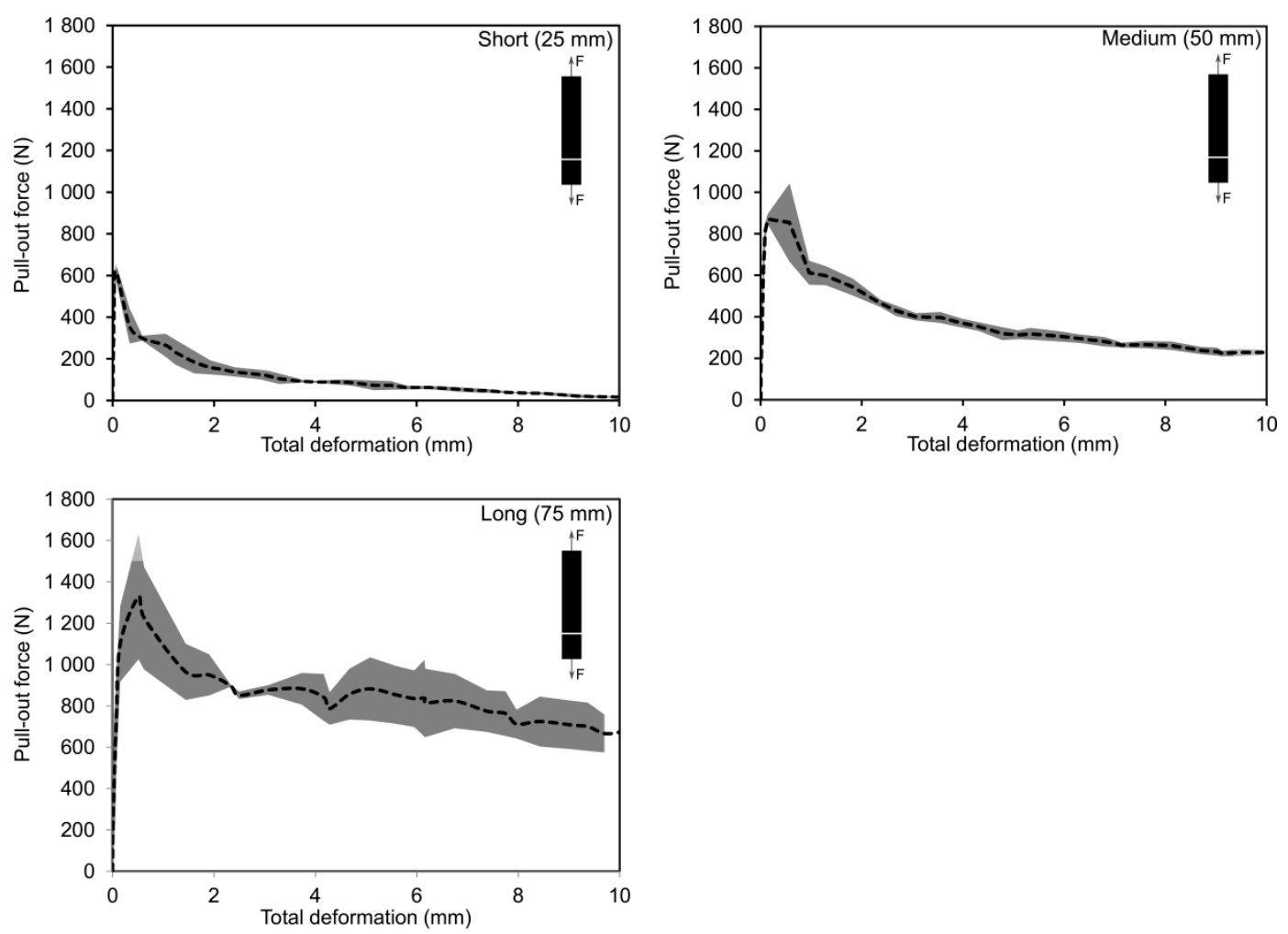

Fig. 5 Pull-out test results for specimens with varying embedment lengths: pull-out force versus deformation with scatter based on standard error.

A suitable local bond stress-slip relationship, when applied in a component level model, should generate results that correlate with the measured bond behaviour of the TRC plate specimen, i.e. global level. The shape of the local bond stress-slip function is dependent on numerous parameters, e.g. material properties of the concrete matrix, reinforcement geometry and surface, as well as the configuration and stiffness of the mesh cross-threads. Numerical or analytical methods are commonly applied to estimate a local bond-slip function. The local bond stressslip functions for carbon reinforced TRC were initially calibrated to match the experimental results in Williams Portal et al. (2014). A first estimate of a local bond-slip function was made according to the experimental results related to the test specimens constituting a short embedment length. This first estimate was then used as input in a global analysis resulting in a force versus crack opening relation. From comparisons with the measured results, the local bond versus slip was corrected in several steps until reasonable agreement was found on the global level in relation to the TRC component behaviour. This calibrated local behaviour provided in Fig. 6 underwent further adaption in terms of the estimated contact perimeter which is why this curve slightly differs from that presented in Williams 
Portal et al. (2014). Moreover, this local bond behaviour was subsequently applied in the developed numerical model simulating the four-point bending of the TRC slabs (see Section 5).

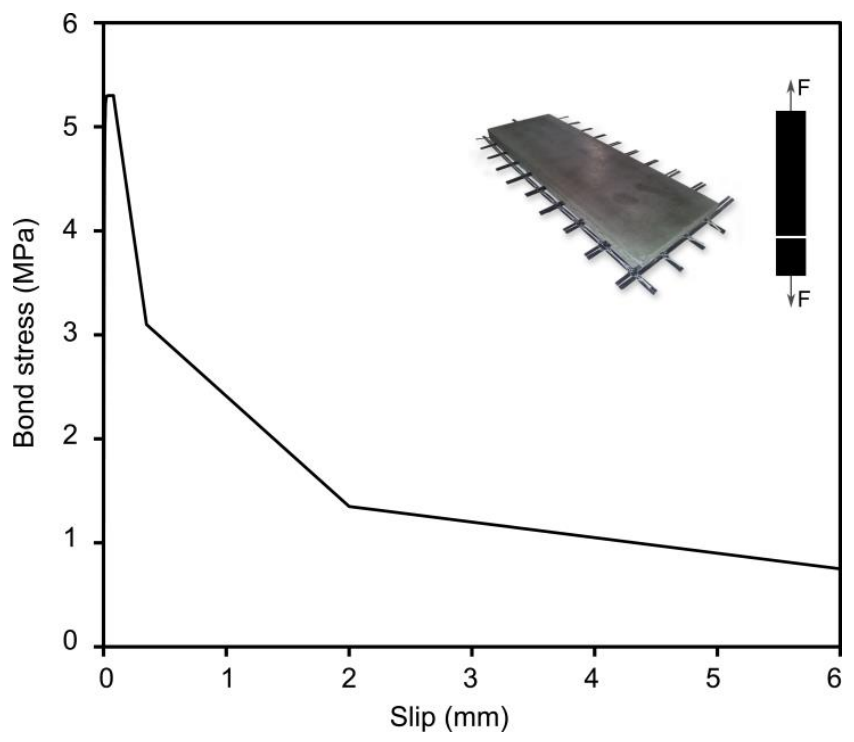

Fig. 6 Calibrated local bond-slip relationship.

\section{Investigation using FE-modelling}

A non-linear macroscale 2D finite element $(\mathrm{FE})$ model was developed based on the component level four-point bending tests related to the $50 \mathrm{~mm}$ thick TRC slabs reinforced by carbon textile fabric. The commercial software DIANA (DIsplacement ANAlyser) with pre- and post-processor Midas FX+ was used to perform the analyses. The ability to interconnect the experimental findings from the various investigated levels, i.e. material and interaction, to the TRC component level was studied by means of the developed model. The experimental results related to the TRC component level from the four-point bending tests were used to validate the outcome of the FE model. Moreover, through these numerical analyses it was important to gain further insight in the failure mode, as well as to identify difficulties and uncertainties in the modelling of TRC. Preliminary modelling work was also carried out in related work by Pettersson and Thorsson (2014). 


\subsection{Model}

The entire geometry of the specimen and experimental setup were modelled in order to be able to yield a crack development pattern comparable to the experimental results of the four-point bending (see Fig. 7). The aforementioned geometry, material properties (material level, Section 2) and bond-slip relationship (interaction level, Section 4.2) were used as input data in the model. Details pertaining to the applied material models are described in the following section. An element size of $2.5 \times 2.5 \mathrm{~mm}$ was selected for the entire geometry. The point load was applied as a fixed deformation and equilibrium was solved using secant tangent iterations which yielded the most stable solution. The selfweight was assumed to be negligible in the analysis as it was found to have a minor influence on the overall results such that it's bending moment corresponded to $2 \%$ of the total bending moment of the applied load. Deformation controlled loading means that the behaviour, especially during the cracking state, can be followed more accurately and that the results can be more easily compared to the test results. A rigid beam connection as a statically determinate system was included in the model to enable the deformation-controlled loading for more than one point load as recommended in Broo et al. (2008) (see Fig. 7). The nodes corresponding to the location of the point loads $(P / 2)$ on the specimen had the same displacement in the y-direction as the end nodes of the rigid links connected to the rigid beam; displacements in the $\mathrm{x}$-direction were not tied between these nodes. The rigid beam was restrained at one end along the $\mathrm{x}$-axis and rotation about the z-axis. To avoid stress concentrations or singularities at the locations of reaction forces and applied loads (i.e. singular nodes), dummy beams (L6BEN, 2 nodes), with low stiffness and density, were introduced at these points, to allow for the interaction of the surrounding nodes. This interaction can be further distinguished as eccentricity tying, wherein surrounding slave nodes were eccentrically connected to a master node (see Fig. 7). In this case, the translation along the $y$-axis and rotation about the $\mathrm{z}$-axis corresponding to the slave nodes were eccentrically connected to the centre master node. 


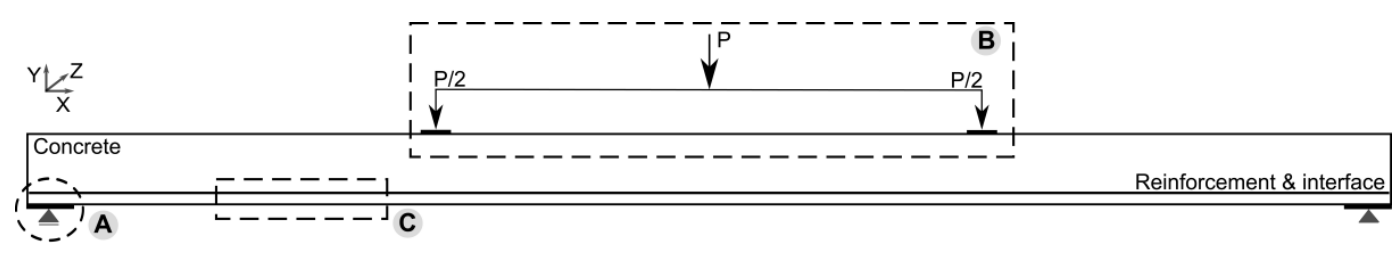

A Dummy beam
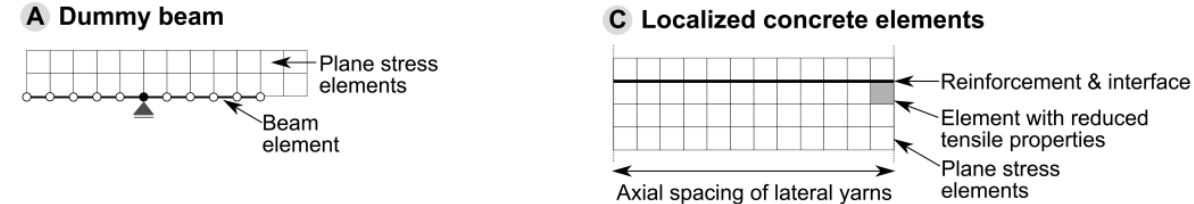

B Rigid beam connection

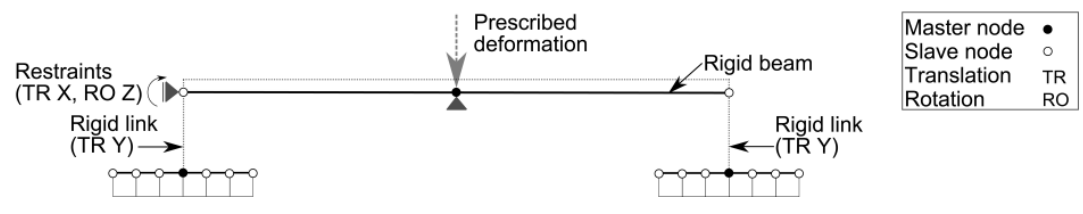

Fig. 7 Idealized FE-model and special features.

The concrete matrix and textile reinforcement were modelled using 2D quadrilateral plane stress elements (Q8MEM, 4 nodes) and 1D truss-bar elements (L2TRU, 2 nodes), respectively. The Q8MEM elements are based on linear interpolation and default Gauss integration $(2 \times 2)$, while the $L 2 T R U$ elements are directly integrated (1-point). The interface of the matrix and reinforcement was defined by 2D line-interface elements with bond-slip relationship ( $L 8 I F, 4$ nodes) which has nodes at the same coordinates as the connecting concrete elements. The purpose of the interface elements is to allow slip while still transferring stress between the concrete and the textile reinforcement. The connectivity between the element types is further described in Pettersson and Thorsson (2014) and Williams Portal et al. (2013).

\subsection{Material models}

\subsubsection{Textile reinforcement}

The textile reinforcement in the longitudinal direction of the rectangular TRC slab was bundled in a monolithic bar (see Fig. 8) similar to what has been applied in other modelling approaches (Azzam and Richter 2011; Holler et al. 2004;

Williams Portal et al. 2013; Williams Portal et al. 2014). The monolithic bar is assumed to have one bond interface with the concrete matrix which therefore neglects the actual uneven bond distribution across the yarn structure. Considering 
a cross-sectional width of $d x$, a number of longitudinal yarns are positioned according to a given centre to centre yarn spacing, $s$, within $d x$. Each individual longitudinal yarn has a contact perimeter assumed to be circular, $C_{\mathrm{f}}$, and a circular area, $A_{\mathrm{f}}$. An equivalent contact perimeter, $C_{\mathrm{t}, 1}$, and area, $A_{\mathrm{t}, \mathrm{l}}$, of the monolithic bar are computed by multiplying $C_{\mathrm{f}}$ and $A_{\mathrm{f}}$ respectively by the number of individual longitudinal yarns found within $d x$.

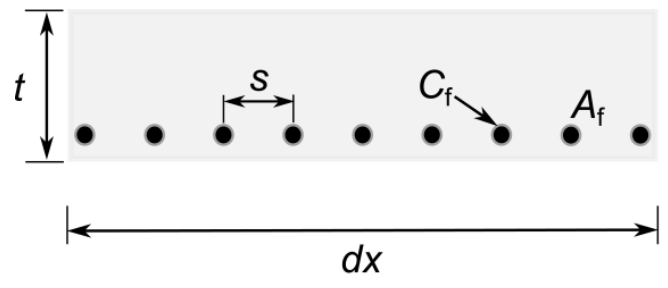

Individual longitudinal yarns

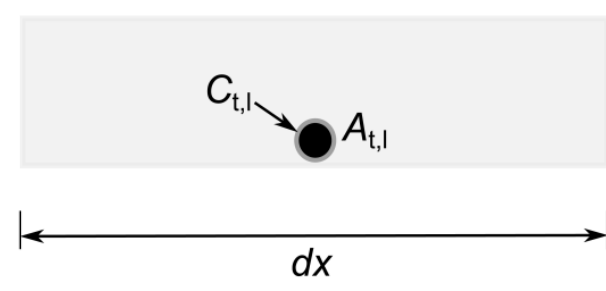

Monolithic bar

Fig. 8 Depiction of the monolithic bar assumption ( $t$ is the thickness of the cross-section and $\mathrm{s}$ is the centre-centre yarn spacing).

The tensile properties of the carbon textile reinforcement were not explicitly quantified in this work, such that the properties made available by the producer were applied in the FE-model (see Table 1). The monolithic bar was assigned a linear-elastic stress-strain law with no limiting tensile strength. To describe the interaction between the textile reinforcement and the concrete matrix, so-called bond behaviour, the local bond stress-slip relationship previously presented in Fig. 6 was assigned to the 2D line interface elements.

Modelling with two interfaces between the external and internal filaments have indicated insignificant differences when compared to modelling with one bond interface (Holler et al. 2004). The quantification of the relative displacement between the external and internal filaments would require an iterative and time consuming process which is thought to be more relevant for more detailed modelling scales, i.e. meso- and microscales. Nevertheless, it should be mentioned that the bond behaviour included in this model takes into consideration the effect of the lateral yarns of the fabric on the pull-out of one yarn as a result of the test specimen configuration. 


\subsubsection{Concrete matrix}

The fine-grained concrete matrix was modelled as a homogeneous material using the properties presented in Section 2.2. The compressive strength and tensile splitting strength of the concrete were experimentally quantified and the fracture energy and modulus of elasticity were estimated using fib Model Code 2010 (2013). The mechanical behaviour of the concrete material was assumed to follow typical curves for compressive and tensile behaviours provided by TNO DIANA (2014). Furthermore, a total strain based crack model with rotating crack was defined for the fine-grained concrete, wherein the crack direction continuously rotates according to the principal directions of the strain vector. This model includes both the tension softening and compressive behaviours, which were modelled by non-linear Hordijk tension softening and Thorenfeldt compression curves available in TNO DIANA (2014). Since the Thorenfeldt curve is based on the compressive strength of cylinders with a length of $300 \mathrm{~mm}$, it was found necessary to correct the post-peak part of the curve. In this case, the correction was effectuated according to a scaling factor (LTHORE) implemented in TNO DIANA (2014). The modification of the curve, depicted in Fig. 9 allowed for the localization of strains in single element rows. Also, a crack band width equal to the element size $(2.5 \mathrm{~mm})$ was chosen as the cracks generally localized in single element rows.

(a)

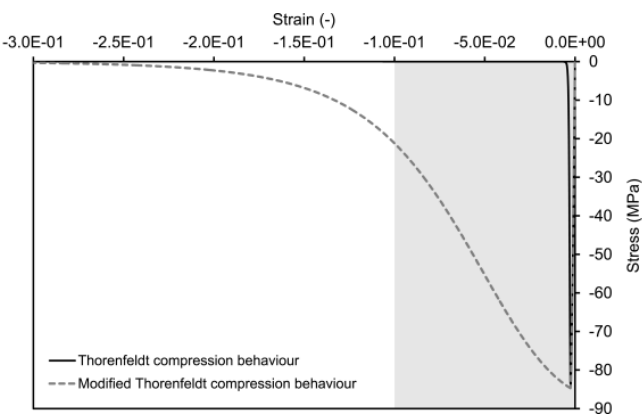

(b)

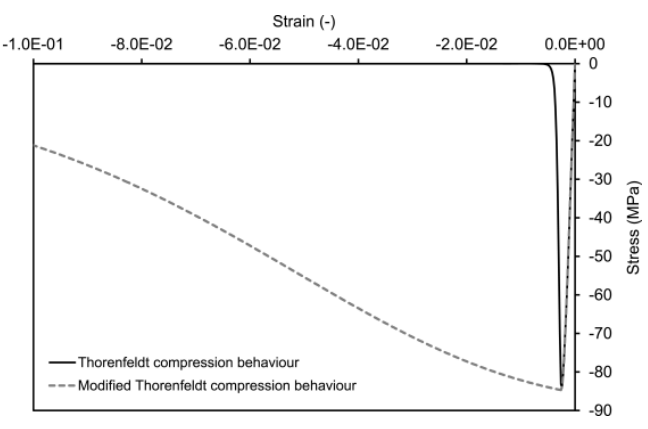

Fig. 9 Modified versus unmodified Thorenfeldt compression behaviours (a) and emphasis on the shift of strain starting at the peak compressive strength (b). Modification based on scaling factor LTHORE in TNO DIANA (2014).

Another feature which was incorporated in the model was the inclusion of socalled voids created by the assumed exclusion of the lateral yarns of the fabric as 
illustrated in Fig. 7. As well, it is a known fact that stress concentrations and crack formation typically occur at the lateral yarn locations (Azzam and Richter 2011; Krüger 2004), thus justifying the need for the localized adjustment of the tensile properties of the concrete. To take this feature into account, the tensile strength and fracture energy of localized concrete elements situated at the reinforcementmatrix interface were decreased in relation to the 'loss of concrete area'. It is to say that the approximate cross-sectional area of the lateral yarn $\left(1.83 \mathrm{~mm}^{2}\right)$ was subtracted from the concrete element area $\left(6.25 \mathrm{~mm}^{2}\right)$. The ratio between the reduced area and the total area of the concrete element resulted in the estimated remaining capacity of the concrete element in the location of a lateral yarn (71\%). As an initial estimation, the tensile strength and fracture energy previously mentioned in Section 2.2 were reduced by the same factor (29\%) leading to 3.3 $\mathrm{MPa}$ and $70 \mathrm{~N} / \mathrm{m}$, respectively.

\subsection{FE results}

\subsubsection{General flexural behaviour}

The flexural behaviour along with the failure mode could be simulated within a reasonable level of accuracy using the developed 2D macroscale model of the presented four-point bending test. To observe the correlation between the numerical and experimental results (see Fig. 4), the respective flexural load versus midspan deflection relationships were plotted against each other. Based on the numerical results in Fig. 10, first cracking $(A)$ occurred at a load level of $4.42 \mathrm{kN}$ and a deflection of $0.75 \mathrm{~mm}$. Multiple cracking took place thereafter which was followed by a deformation hardening behaviour with a comparable stiffness to that of the experimental curves. The TRC specimen eventually underwent a bond failure in the analysis at an ultimate load of $9.58 \mathrm{kN}$ and deflection of $25.30 \mathrm{~mm}$, which is marked by the growth of the end slip at the outer edges of the specimen as further described in Section 5.3.2. Moreover, a slight overestimation of the load at first cracking was obtained which occurred at a lower deflection value as presented in Table 3. As for the load and midspan deflection at failure, these values were marginally higher than the experimental results which could be due to the following factors: scatter in pull-out test results leading to uncertainty in local bond stress-slip curve, overestimation of the deformation, i.e. total slip, due to the exclusion of internal filament slip, as well as the exclusion of the reduction of the 
cross-sectional area of yarns caused by successive failure of filament rupture (Lepenies 2007). Furthermore, the frictional zone of the local bond stress-slip curve, i.e. bond stress decline after peak, was not adequately captured. The configuration of the pull-out test setup and choice and placement of measurement devices, i.e. LVDT, did not allow for the precise measurement of the pull-out failure due to a sudden release of the LVDT upon failure. Other modifications to the model could include the effect of the end support pressure and/or the impact of the curvature (Hegger et al. 2008; Voss et al. 2006) on the bond; these effects would however cause an increased capacity. Lastly, it is thought that the inclusion of experimental compressive and tensile behaviours pertaining to the given finegrained concrete could also help improve the correlation between the numerical and experimental results.

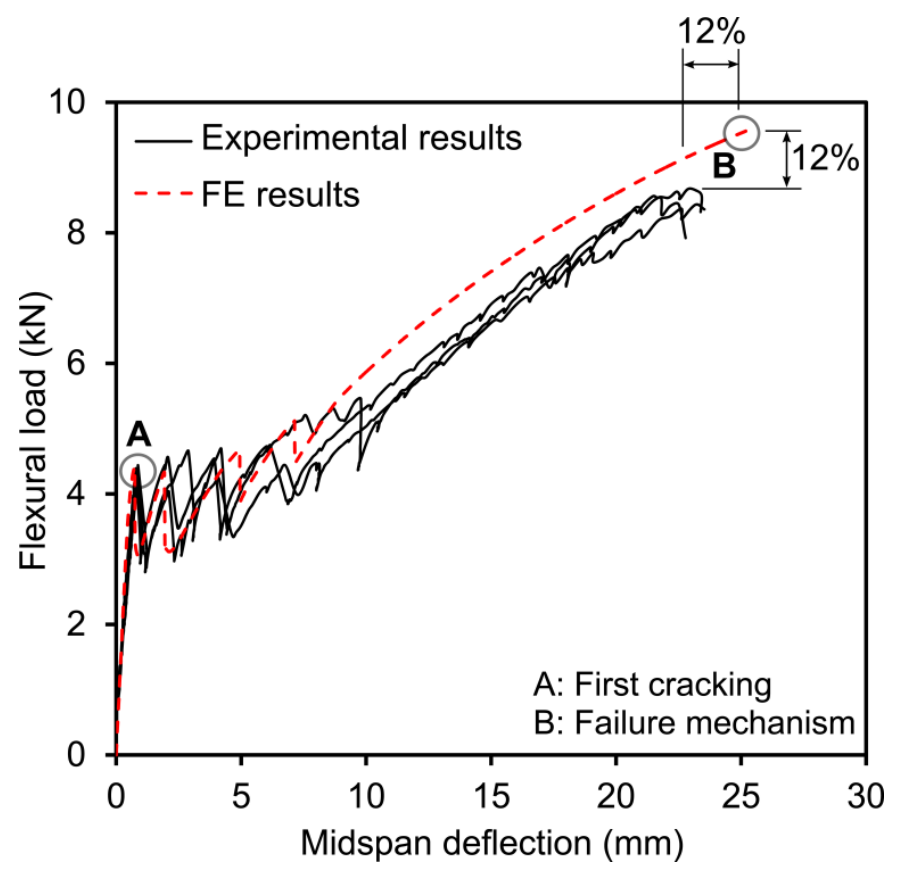

Fig. 10 Comparison of experimental and FE-results.

Table 3 Comparison between average experimental flexural results and FE-analysis.

\begin{tabular}{llll}
\hline Results & $\begin{array}{l}\text { Avg. experimental values } \\
(\text { Std dev })\end{array}$ & FE-analysis & $\begin{array}{l}\text { Percentage error } \\
(\%)\end{array}$ \\
\hline $\begin{array}{l}\text { Flexural load at first } \\
\text { cracking, } F_{\mathrm{cr}}(\mathrm{kN})\end{array}$ & $4.34(0.09)$ & 4.42 & 2 \\
$\begin{array}{l}\text { Midspan deflection at } F_{\mathrm{cr}}, \\
\delta_{\mathrm{cr}}(\mathrm{mm})\end{array}$ & $0.85(0.05)$ & 0.75 & -11 \\
$\begin{array}{l}\text { Ultimate flexural load, } \\
F_{\mathrm{u}}(\mathrm{kN})\end{array}$ & $8.54(0.12)$ & 9.58 & 12 \\
$\begin{array}{l}\text { Midspan deflection at } F_{\mathrm{u}}, \\
\delta_{\mathrm{u}}(\mathrm{mm})\end{array}$ & $22.61(0.72)$ & 25.30 & 12 \\
\hline
\end{tabular}




\subsubsection{Crack pattern and failure mechanism}

To gain a deeper understanding of the numerical results, contour plots depicting key parameters, i.e. concrete strain, reinforcement stress, bond stress and slip, were evaluated. Contour plot, particularly related to first cracking and failure, are shown in Fig. 11 (a) and (b), respectively. At first cracking, it can be seen in the contour plot corresponding to concrete strain in Fig. 11 (a) that cracking appeared as the tensile strains localized in the concrete near midspan. At this point, the stress states of the reinforcement and at the interface as well as the slip are relatively low. From the concrete strain contour plot at failure, see Fig. 11 (b), a total of five cracks developed following a similar crack pattern to that observed in the experiments. A maximum tensile stress of $2430 \mathrm{MPa}$ in the reinforcement was noted which can be compared with the tensile strength of the fabric based on the producer values of approximately $1700 \mathrm{MPa}$ (see Table 1). Due to the underlying uncertainty of the actual tensile strength however, it could only be presumed that the reinforcement may have undergone rupture in localized areas at crack locations.

(a)
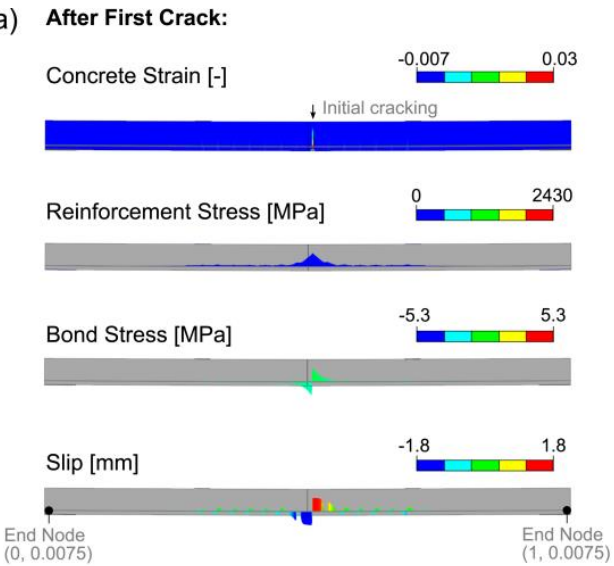

(b) At Failure:

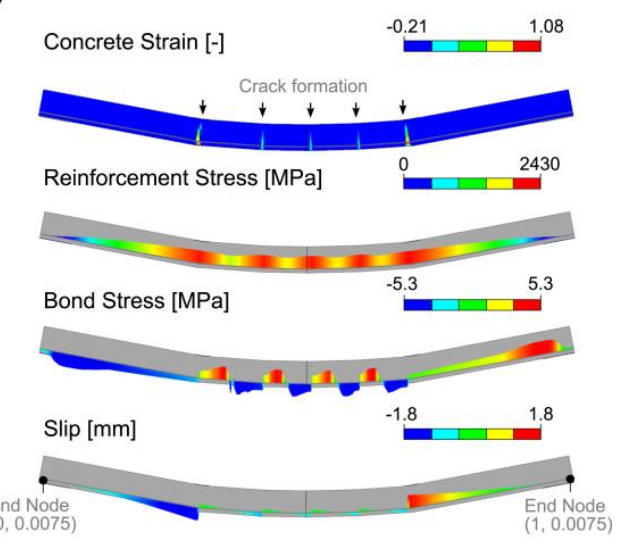

(c)

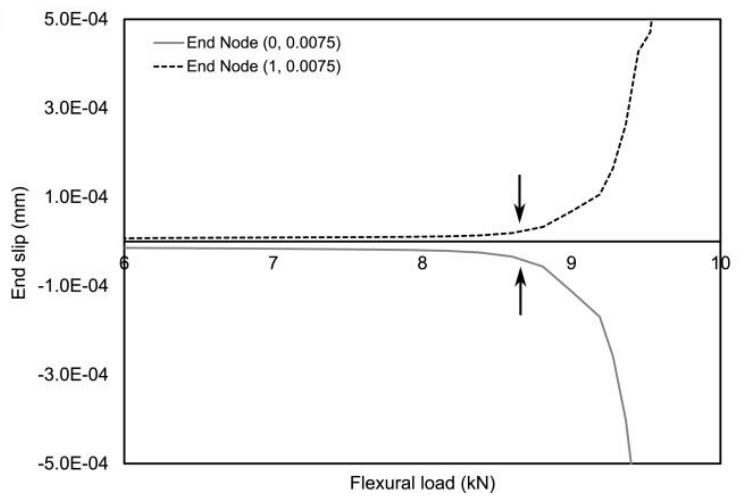

Fig. 11 Contour plots after first cracking (a) and at failure (b) along with the end slip versus load relationship (c). 
Additionally, to further verify the failure mode in the analysis as an anchorage failure, the growth of the end slip at both ends of the interface was plotted against the flexural load, see Fig. 11 (c). The scale was adjusted to show the growth before failure occurs. From these results, it can be observed that the end slip started to grow at a load of approximately $8.8 \mathrm{kN}$ which led to an eventual anchorage failure in the analysis as the end slip significantly increased. Based on this numerical analysis, it can be supposed that the failure mechanism which took place in the four-point bending experiments was indeed an anchorage failure. The partial rupture of the textile fabric could however not be captured in this particular model, but certainly this partial rupture contributed to the ultimate failure in the experiments.

\section{Conclusions}

This paper focused on presenting an approach linking experimental methods from material, interaction and component levels to numerical investigations for thin rectangular TRC slabs reinforced by carbon textile fabric. The material level properties were experimentally and analytically quantified for the cementitious matrix, while the textile properties were values from the producer. The interaction level was represented by a calibrated local bond-slip curve obtained from pull-out tests. The component level was characterized by the one-way flexural behaviour of these slabs which resulted in multiple cracking and deformation hardening. The failure mechanism was however difficult to characterize during testing yet it was observed to be a combination failure of pull-out and partial filament rupture.

The 2D macroscale model developed for the four-point bending test of the carbon reinforced TRC slabs generated comparable results to the experimental ones with an adequate level of accuracy. The analyses resulted in a slight over prediction of the ultimate capacity and revealed that failure was governed by bond; this failure mode was difficult to determine in the four-point bending tests alone but seem trustworthy when looking at the results together. The underlying accuracy of the modelling output of the flexural behaviour of the TRC slab can be further improved by refining the experimental methods applied on the various levels of investigation and by increasing the number of experimental samples. 


\section{Acknowledgments}

The presented research was funded by the European Community's Seventh Framework

Programme under grant agreement NMP2-LA-2009-228663 (TailorCrete) and FORMAS (Homes

for Tomorrow). More information about the research projects, TailorCrete and Homes for

Tomorrow, can be found at www.tailorcrete.com and www.homesfortomorrow.se, respectively.

\section{References}

Azzam A, Richter M (2011) Investigation of Stress Transfer Behavior in Textile Reinforced Concrete with Application to Reinforcement Overlapping and Development Lengths. Paper presented at the 6th Colloquium on Textile Reinforced Structures (CTRS6), Dresden, Germany,

Banholzer B, Brockmann T, Brameshuber W (2006) Material and bonding characteristics for dimensioning and modelling of textile reinforced concrete (TRC) elements Mater Struct 39:749-763 doi:10.1617/s11527006-9140-x

Brameshuber W (ed) (2006) Report 36: Textile Reinforced Concrete-State-of-theArt Report of RILEM TC 201-TRC vol 36. RILEM publications,

Broo H, Lundgren K, Plos M (2008) A guide to non-linear finite element modelling of shear and torsion in concrete bridges. Report 2008:18, Chalmers University of Technology

Colombo I, Magri A, Zani G, Colombo M, di Prisco M (2013) Erratum to: Textile Reinforced Concrete: experimental investigation on design parameters Mater Struct 46:1953-1971 doi:10.1617/s11527-013-0023-7

EN 1992-1-1 (2008) EN 1992-1-1:2005 Eurocode 2: Design of concrete structures. Comité Européen de Normalisation (CEN),

EN 12390-3 (2009) Testing hardened concrete - Part 3: Compressive strength of test specimens. Comité Européen de Normalisation (CEN),

EN 12390-6 (2009) Testing hardened concrete - Part 6: Tensile splitting strength of test specimens. Comité Européen de Normalisation (CEN),

fib Model Code 2010 (2013). Fédération Internationale du béton, Lausanne

Hartig J, Jesse F, Häußler-Combe U Influence of different mechanisms on the constitutive behaviour of textile reinforced concrete. In: 4th Colloquium on Textile Reinforced Structures (CTRS4), Dresden, Germany, 2009.

Hegger J, Schneider H, Voss S, Bergmann I (2008) Dimensioning and application of textile-reinforced concrete ACI Special Publication 250

Hegger J, Will N, Bruckermann O, Voss S (2006) Load-bearing behaviour and simulation of textile reinforced concrete Mater Struct 39:765-776 doi:10.1617/s11527-005-9039-y

Hegger J, Voss S (2008) Investigations on the bearing behaviour and application potential of textile reinforced concrete Engineering structures 30:20502056

Holler S, Butenweg C, Noh SY, Meskouris K (2004) Computational model of textile-reinforced concrete structures Computers \& Structures 82:19711979 doi:10.1016/j.compstruc.2004.03.076

Jesse F (2004) Tragverhalten von Filamentgarnen in zementgebundener Matrix (Load bearing behaviour of filament yarns in a cementitious matrix). Technische Universität Dresden 
Krüger M (2004) Vorgespannter textilbewehrter Beton (Prestressed textile reinforced concrete). Dissertation, University of Stuttgart

Lepenies IG (2007) Zur hierarchischen und simultanen multi-skalen-analyse von textilbeton (On the Hierarchical and Integrated Multi Scale Analysis of Textile Reinforced Concrete). Dissertation, Technische Universität Dresden

Lorenz E, Ortlepp R (2012) Bond behavior of textile reinforcements-development of a pull-out test and modeling of the respective bond versus slip relation. In: High Performance Fiber Reinforced Cement Composites 6. Springer, pp 479-486

Lorenz E, Schütze E, Schladitz F, Curbach M (2013) Textilbeton-Grundlegende Untersuchungen im Überblick Beton und Stahlbetonbau 108:711-722

Micelli F, Nanni A (2004) Durability of FRP rods for concrete structures Construction and Building Materials 18:491-503

Orosz K, Blanksvärd T, Täljsten B, Fischer G (2010) From material level to structural use of mineral-based composites - an overview Advances in Civil Engineering

Peled A, Bentur A, Yankelevsky D (1999) Flexural performance of cementitious composites reinforced with woven fabrics Journal of materials in civil engineering 11:325-330

Pettersson M, Thorsson P (2014) FE-modelling of Textile Reinforced Concrete Facade Elements. Master's Thesis, Chalmers University of Technology

Rempel S, Kulas C, Hegger J (2015) Bearing Behavior of Impregnated Textile Reinforcement. Paper presented at the 3rd ICTR International Conference on Textile Reinforced Concrete Aachen, Germany,

Scheffler C, Gao S, Plonka R, Mäder E, Hempel S, Butler M, Mechtcherine V (2009) Interphase modification of alkali-resistant glass fibres and carbon fibres for textile reinforced concrete I: Fibre properties and durability Composites Science and Technology 69:531-538

Schladitz F, Frenzel M, Ehlig D, Curbach M (2012) Bending load capacity of reinforced concrete slabs strengthened with textile reinforced concrete Engineering structures 40:317-326

Shams A, Horstmann M, Hegger J (2014) Experimental investigations on TextileReinforced Concrete (TRC) sandwich sections Composite Structures 118:643-653

TNO DIANA (2014) Finite Element Analysis User's Manual - Release 9.5.

Williams Portal N, Lundgren K, Walter AM, Frederiksen JO, Thrane LN (2013) Numerical Modelling of Textile Reinforced Concrete. Paper presented at the VIII International Conference on Fracture Mechanics of Concrete and Concrete Structures, Toledo, Spain, 10-14 March,

Williams Portal N, Perez Fernandez I, Thrane Nyholm L, Lundgren K (2014) Pull-out of textile reinforcement in concrete Construction and Building Materials 71:63-71

Voss S, Hegger J, Hegger J, Brameshuber W, Will N Dimensioning of textile reinforced concrete structures. In: Proceedings of the 1st International RILEM Symposium on textile reinforced concrete, RILEM Publication SARL, France, 2006. pp 151-160

Xu S, Li H (2007) Bond properties and experimental methods of textile reinforced concrete Journal of Wuhan University of Technology--Materials Science Edition 22:529-532 doi:10.1007/s11595-006-3529-9 
Yin S, Xu S, Li H (2013) Improved mechanical properties of textile reinforced concrete thin plate Journal of Wuhan University of Technology-Mater Sci Ed 28:92-98 doi:10.1007/s11595-013-0647-z

Zastrau B, Richter M, Lepenies I (2003) On the Analytical Solution of Pullout Phenomena in Textile Reinforced Concrete Journal of Engineering Materials and Technology 125:38-43 